\title{
ANALISA HARMONIK PASANG SURUT DENGAN METODE ADMIRALTY PADA STASIUN BERJARAK KURANG DARI 50 KM
}

\section{HARMONIC ANALYSIS WITH ADMIRALTY METHODE ON SEA TIDES STATION LESS THAN $50 \mathrm{KM}$}

\author{
Dina Fitriana ${ }^{1 *}$, Nadya Oktaviani ${ }^{2}$, Isna Uswatun Khasanah ${ }^{3}$ \\ ${ }^{1}$ Pusat Jaring Kontrol Geodesi dan Geodinamika, Badan Informasi Geospasial \\ ${ }^{2}$ Pusat Penelitian Promosi dan Kerjasama, Badan Informasi Geospasial \\ ${ }^{3}$ Fakultas Teknik Sipil dan Perencanaan, Institut Teknologi Padang \\ ${ }^{*}$ E-mail: dina.fitriana@big.go.id
}

\begin{abstract}
ABSTRAK
Pasang surut laut merupakan sebuah fenomena naik dan turunnya permukaan air laut di bumi akibat pengaruh gravitasi benda luar angkasa, terutama matahari dan bulan. Pengamatan pasang surut laut sangat penting dalam penentuan referensi vertikal, untuk menyatukan data-data pengukuran di laut dan di daratan agar dapat diterjemahkan dalam satu kesatuan sistem pemetaan. Indonesia sebagai negara kepulauan terbesar di dunia yang memiliki luas laut 3,25 juta $\mathrm{km} 2$ dari 7,81 juta $\mathrm{km} 2$ total luas wilayah Indonesia, sudah seharusnya memiliki stasiun pasang surut yang tersebar merata di seluruh Indonesia. Penempatan stasiun tersebut juga harus tepat lokasi karena setiap perairan memiliki karateristik tersendiri. Badan Informasi Geospasial (BIG) mengelola 138 stasiun pasang surut (pasut) yang terdistribusi di seluruh wilayah Indonesia. Stasiun pasut tersebut pada umumnya ditempatkan di dermaga/pelabuhan, sehingga jarak antar staisun pasang surut menyesuaikan ketersediaan dermaga yang ada. Pada penelitian ini dilakukan analisa harmonik pasut dengan metode admiralty pada stasiun pasut BIG yang jarak antar stasiunnya kurang dari $50 \mathrm{~km}$, disumsikan tipe pasut di lokasi yang berdekatan tersebut sama. Lokasi penelitian adalah stasiun pasut Ulee Lhue dibandingkan dengan stasiun pasut Malahayati, stasiun pasut Pel. Ciwandan dibandingkan dengan stasiun pasut Serang, stasiun pasut Sunda Kelapa dibandingkan dengan Pondok Dayung, dan stasiun pasut Pameungpeuk dibandingkan dengan stasiun pasut Pamayangsari. Hasil penelitian menunjukkan bahwa tipe pasut dilokasi yang dibandingkan tersebut memiliki karakteristik yang sama.
\end{abstract}

Kata kunci: pasang surut, metode admiralti, geospasial, referensi vertikal

\section{ABSTRACT}

Sea tides are a phenomenon of rising and falling sea levels on the earth due to the influence of space objects, especially the sun and the moon. Observation of sea tides is very important in determining vertical references, to unite measurement data at sea and on land so that they can be translated into a single mapping system. Indonesia as the largest archipelagic country in the world which has a sea area of 3.25 million $\mathrm{km} 2$ from 7.81 million $\mathrm{km} 2$ of the total area of Indonesia, should have tidal stations that are spread evenly throughout Indonesia. Placement of the station must also be right location because each waters has its own characteristics. The Geospatial Information Agency (BIG) manages 138 tidal stations (tidal) distributed throughout Indonesia. The tidal station is generally placed in the dock / port, so that the distance between tidal stations adjusts the availability of existing docks. In this study a tidal harmonic analysis was carried out using the admiralty method at BIG tide stations with less than $50 \mathrm{~km}$ distance between stations, assuming the tidal type in the adjacent location was the same. The research location is the Ulee Lhue tide station compared to the Malahayati tide station, Pel. Ciwandan compared to Serang tidal station, Sunda Kelapa tide station compared to Pondok Dayung, and Pameungpeuk compared to Pamayangsari tidal station. The results of the study showed that the harmonic analysis and tidal type of the location were the same..

Keywords: sea tides, admiralty, geospasial, vertical references 


\section{PENDAHULUAN}

Badan Informasi Geospasial (BIG) khususnya Pusat Jaring Kontrol Geodesi dan Geodinamika memiliki salah satu tugas pokok yang mengarah pada penyediaan layanan referensi vertikal pasut yaitu datum pasut dan model pasut. Idealnya datum pasut dan model pasut dibentuk dari pengamatan pasut minimal 18,5 tahun, karena dalam rentang waktu ini merupakan waktu yang dibutuhkan node bulan dan ekliptik dalam posisi yang saling berhimpit (Ali dkk., 1994). Hasil perhitungan ini yang kemudian dapat digunakan untuk menentukan chart datum. Chart datum sendiri merupakan referensi ketinggian yang digunakan untuk pembuatan peta laut maupun darat (Ongkosongo, 1989).

Saat ini BIG mengupayakan agar data pasut dengan rentang waktu minimal 18,6 tahun tersebut tersedia dalam kondisi baik. Salah satu cara yang diupayakan adalah dengan melakukan pemasangan dan pemantauan stasiun pasut yang tersebar di wilayah tanah air. Pemilihan lokasi pemasangan sangat berpengaruh pada kondisi staisun pasut itu sendiri. Sehingga kriteria pembangunan stasiun pasut menjadi faktor penting dalam penyediaan instrument pengamatan pasut. Salah satu kriteria yang dimaksud adalah pada lokasi yang aman, permanen dan mudah diakses, agar stasiun pasut yang dikelola BIG dapat bertahan lama (SNI 7924:2013). Hingga tahun 2018 penempatan stasiun pasang surut menempel pada bangunan permanen seperti dermaga dan bangunan permanen lainnya disekitar dermaga/pelabuhan. Komponen dari sistem pasut BIG sebagai berikut, (Dina dan Irfan, 2018) :

a. Sensor. Sensor yang menggunakan beberapa buah sensor di lapangan yang bertujuan untuk mendapatkan data sebanyak-banyaknya sesuai dengan prinsip pengukuran geodesi bahwa makin banyak data pengukuran makin baik data yang didapatkan.

b. Data Logger, berfungsi untuk merekam data dan mengkonversi kode dari sensor menjadi angka matematis yang dapat dianalisa oleh analis data, serta menyimpan dan mengirimkan data ke server (untuk input Sistem Monitoring) c. Power atau sumber tenaga yang digunakan pada umumnya adalah tenaga surya dengan kekuatan $100 \mathrm{Ah}$.

d. Referensi (komponen referensi berlapis, baru berlaku sejak 2018). Yang dimakasud referensi bacaan disini adalah acuan bacaan yang digunakan oleh sensor pasang surut. Referensi utama adalah palm, yang kemudian palm ini diikatkan ke BM-Pasut. Backup referensi juga ada yang berfungsi menjaga bacaan tetap pada nilai awalnya yaitu TAP, PIN, dan TIP. TAP adalah titik acuan pasut, PIN adalah titik acauan di bangunan pasut dan TIP adalah titik ikat pasut. Selain itu ditambahkan juga GPS@Pasut yaitu pilar GPS di atas rumah pasut. Hubungan dari masing-masing referensi dapat dilihat pada gambar 3 . Referensi Stasiun Pasang Surut

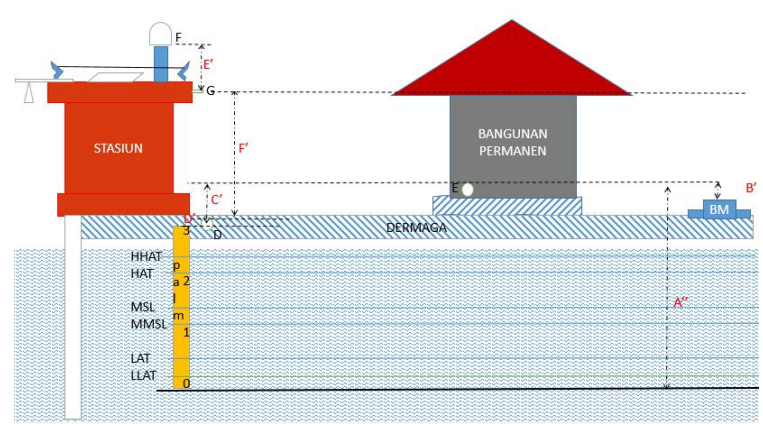

Keterangan:

A" : Beda Tinggi antara titik nol palem (0 meter) ke BM (dihitung)

B' : Beda Tinggi dari BM ke TIP (diukur)

C' : Beda Tinggi dari TAP ke TIP (diukur)

D' : Beda Tinggi dari palem (dari angka 3 meter) ke TAP (diukur)

E' : Beda Tinggi dari PIN ke GPS Pasut (diukur)

F' : Beda Tinggi dari TAP ke PIN (diukur)

D : TAP

E : TIP

$\mathrm{F} \quad:$ PIN

G : GPS Pasut

\section{Gambar 1 Referensi Stasiun Pasang Surut}

e. Rumah Pasang Surut (Rumah Pasut) adalah bangunan permenen yang dibangun didermaga bertujuan untuk mengamankan peralatan dari bahaya alam dan bahaya lain yang mengganggu terlaksananya pengamatan pasut. Cek ke gambar 5, untuk meihat rumah stasiun pasang surut.

f. Komunikasi data, menggunakan gprs yang mengirim data semi realtime per 5 menit 
dikirim ke server di Data Center Badan Informasi Geospasial.

g. Operator pasut adalah warga sekitar stasiun yang ditunjuk dengan SK Deputi. Operator ini bertugas mengawasi keamanan stasiun dan membantu perbaikan ringan distasiun seperti penggantian pintu, kusen, atau aki.

Berdasarkan perkembangannya, stasiun pasut tidak hanya digunakan untuk referensi pemetaan, tetapi sangat berperan penting dalam pengamatan naik-turunnya permukaan air laut sehingga menjadi kesatuan yang tidak terpisahkan dari proteksi terhadap abrasi maupun tsunami atau yang biasa dikenal dengan tsunami early warning system (Hidayat, 2010). Mengenai hal ini, BIG telah bekerjasama dengan instansi lainnya (BMKG, BPPT, dan BNPB) untuk memaksimalkan data pasut agar semakin bertambah manfaatnya bagi masyarakat dengan menambah sebaran stasiun pasut di lokasi yang memiliki potensi bencana tsunami. Stasiun pasang surut yang dikelola oleh Badan Informasi Geospasial saat ini berjumlah 138 stasiun yang tersebar di seluruh Indonesia. Dari 138 sebaran stasiun tersebut, teridentifikasi beberapa stasiun yang jaraknya kurang dari $50 \mathrm{~km}$ yaitu stasiun Ulee Lhue dengan Malahayati di Provinsi Aceh, stasiun Pel. Ciwandan dengan Serang di Provinsi Banten, stasiun Sunda Kelapa dengan Stasiun Pondok Dayung di DKI Jakarta dan stasiun Pameungpeuk dengan Pamayang Sari di Provinsi Jawa Barat.

Penelitian ini bertujuan untuk mengamati tipe pasut pada lokasi penelitian yang dilihat berdasarkan hasil analisa harmonik pasut dengan metode Admiralty. Perhitungan pasut dihitung berdasarkan data pengamatan dengan memperhitungkan komponen harmonik yang diketahui frekuensinya. Data komponen pasut ini yang digunakan untuk menentukan tipe pasut pada lokasi perairan tertentu. Semakin panjang data semakin banyak komponen pasut yang dapat diuraikan (Supriyono, 2015). Di Indonesia sendiri, memiliki 4 tipe pasut (Triatmodjo, 1999) yaitu pasang surut harian ganda (semi diurnal tide), pasang surut harian tunggal (diurnal tide), pasang surut campuran condong ke harian ganda (mixed tide prevailing semidiurnal) dan pasang surut campuran condong ke harian tunggal (mixed tide prevailing diurnal). Penelitian ini menguraikan tipe pasut pada lokasi tertentu, jika pada lokasi yang berada kurang dari $50 \mathrm{~km}$ menunjukan tipe pasut yang sama, maka sebaiknya dilakukan relokasi pada salah satu stasiun. Bisa juga dijadikan data tambahan saat pengolahan.

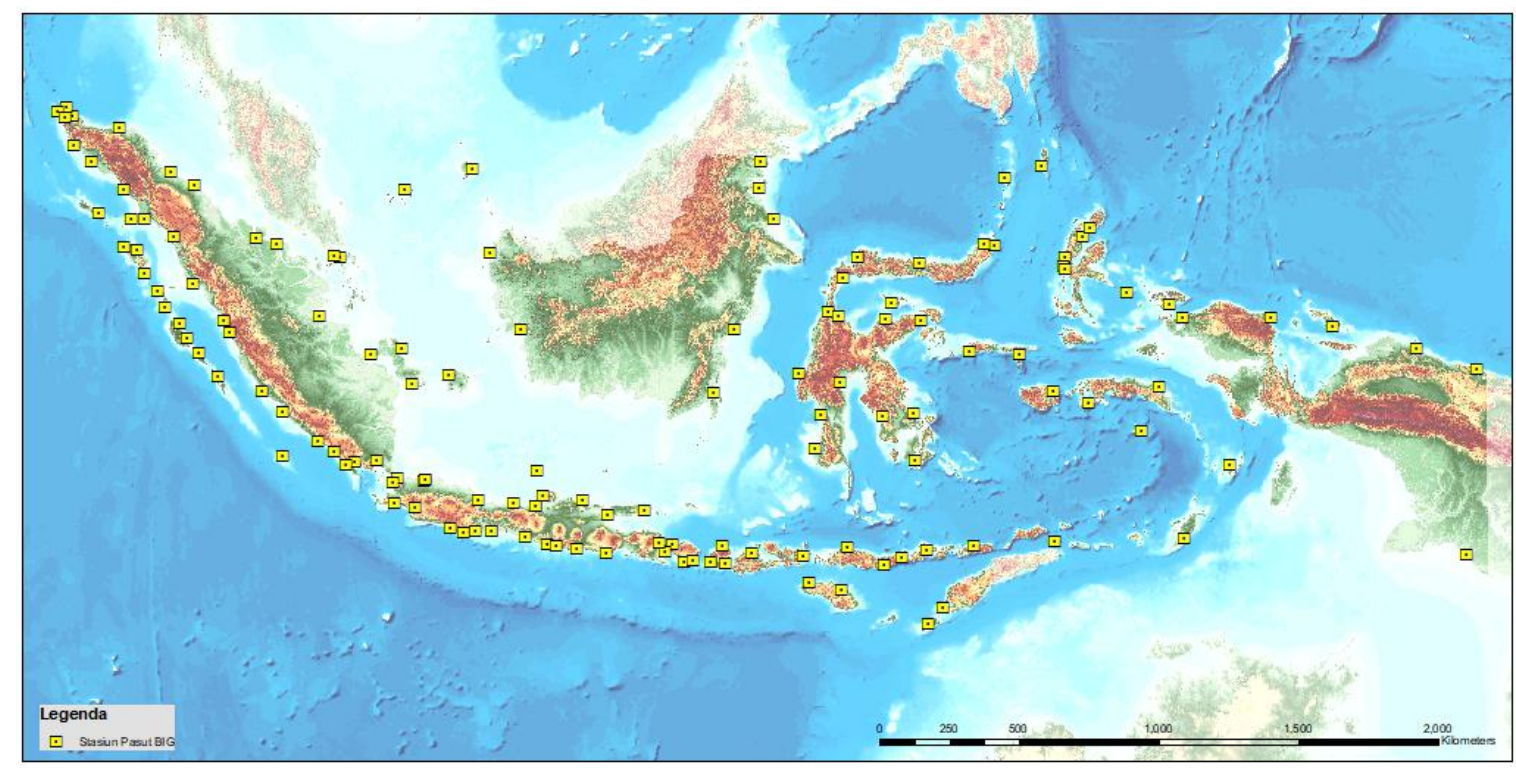

Gambar 1 Sebaran Stasiun Pasang Surut sampai 2018 (sumber : www.ina-sealevelmonitoring.big.go.id/ipasoet/) 


\section{METODE}

Metode Admiralty mulanya dikembangkan oleh A.T. Doodson pada tahun 1921 seorang Direktur Tidal Institute di Liverpool yang digunakan untuk keperluan kantor hidrografi Inggris yaitu British Admiralty. Metode ini tepat digunakan untuk perhitungan pasut dengan rentang data yang pendek seperti 15 piantan dan 29 piantan. Adapun kelemahan dari metode Admiralty ini adalah hanya digunakan untuk pengolahan data-data berjangka waktu pendek dan hasil perhitungan yang relatif sedikit hanya menghasilkan 9 komponen pasang surut (Pariwono, 1989). Karena terbatas pada rentang data yang singkat, sehingga metode ini digunakan pada lokasi yang memiliki keterbatasan data, namun dapat memprediksi kondisi dan karakteristik pasutnya dengan teliti (Ahmad dkk., 2017). Prosesnya perhitungan pasut dengan metode ini memerlukan tabel pendukung yang berisi konstanta perhitungan. Selanjutnya perhitungan dengan metode ini mendapatkan 2 konstanta harmonik yaitu amplitudo (A), dan perbedaan fase $\left(\mathrm{g}^{\circ}\right)$ sehingga analisa tentang tipe pasut dapat dilakukan.

Penelitian ini dilakukan pada beberapa wilayah yaitu :

1. Stasiun pasang surut Ulee Lhue yang terletak di $5^{\circ} 33^{\prime} 59^{\prime \prime} .4 \mathrm{LU}$, dan $95^{\circ}$ 17' 41".3 BT, desa Ulee Lhue, kecamatan Meuraksa, kabupaten Banda Aceh, provinsi Aceh.

2. Stasiun Malahayati terletak pada $5^{\circ}$ 35' $48^{\prime \prime} .58 \mathrm{LU}$ dan $95^{\circ} 31$ ' $28^{\prime} .78 \mathrm{BT}$, desa Lamreh, kecamatan Kreung Raya, kabupaten Aceh Besar, Provinsi Aceh.

3. Stasiun pasang surut Pelabuhan Ciwandan (Pel. Ciwandan) terletak pada $6^{\circ} 01$ ' 3".68177 LS, dan $105^{\circ} 57^{\prime}$ 9".41334 BT, desa Keduh, kecamatan Ciwandan, kabupaten Cilegon, provinsi Banten.

4. Sedangkan stasiun pasang surut Serang terletak pada $6^{\circ} 11^{\prime} 211^{\prime \prime} .21894$
LS, dan $105^{\circ} 50^{\prime} 28^{\prime \prime} .0450$ BT desa Bulukan kecamatan Cinangka kabupaten Serang provinsi Banten.

5. Stasiun pasut Sunda Kelapa terletak pada $6^{\circ} \quad 07^{\prime} \quad 29 " .27 \mathrm{LS}, 106^{\circ} 48^{\prime}$ 34".49 BT, desa Penjaringan, kecamatan Penjaringan, Kota Jakarta Utara, provinsi DKI Jakarta.

6. Stasiun Pondok Dayung terletak pada $6^{\circ} 05^{\prime} 48^{\prime \prime} .03 \mathrm{LS}, 106^{\circ} 52^{\prime} 41^{\prime \prime} .58 \mathrm{BT}$, desa Tanjung Priok kecamatan Tanjung Priok, kota Jakarta Utara, provinsi DKI Jakarta.

7. Stasiun pasut Pameungpeuk terletak pada $7^{\circ} 39^{\prime} 41^{\prime \prime} .508 \mathrm{LS}, 107^{\circ} 40^{\prime}$ 57".360 BT.

8. Stasiun pasut Pemayang Sari terletak pada $7^{\circ} 46^{\prime} 19^{\prime \prime} .452 \mathrm{LS}, 108^{\circ} 05^{\prime}$ $16 ” .08 \mathrm{BT}$.

Jarak antara stasiun pasut Ulee Lhue dengan stasiun pasut Malahayati adalah 31,66 $\mathrm{km}$. Jarak stasiun Pel. Ciwandan dengan stasiun Serang adalah $26.09 \mathrm{~km}$. Jarak stasiun pasut Sunda Kelapa dengan Pondok Dayung $13.05 \mathrm{~km}$. Terakhir, Stasiun pasut Pameungpeuk dengan stasiun Pamayangsari juga memiliki jarak yang kurang dari $50 \mathrm{~km}$, yaitu $49,64 \mathrm{~km}$. Jarak yang dimaksud didapat dengan melakukan pengukuran garis pantai diantara kedua stasiun yang dibandingkan. Sumber data yang digunakan dalam penelitian ini adalah data sekunder berupa data pasang surut Badan Informasi Geospasial (BIG) yang sudah dilakukan validasi dengan spesifikasi sebagai berikut : 
Tabel 1 Wilayah Penelitian dan Spesifikasi Data

\begin{tabular}{|c|c|c|c|}
\hline $\begin{array}{l}\mathbf{N} \\
\mathbf{0 .}\end{array}$ & $\begin{array}{c}\text { Nama } \\
\text { Stasiun }\end{array}$ & $\begin{array}{c}\text { Periode } \\
\text { Data } \\
\text { Th. } \\
2018\end{array}$ & $\begin{array}{c}\text { Interval } \\
\text { Pengamatan }\end{array}$ \\
\hline 1 & $\begin{array}{l}\text { Ulee Lhue - } \\
\text { Provinsi Aceh }\end{array}$ & $\begin{array}{c}17 \text { April } \\
-15 \\
\text { Mei }\end{array}$ & Per 1 Jam \\
\hline 2 & $\begin{array}{l}\text { Malahayati - } \\
\text { Provinsi Aceh }\end{array}$ & $\begin{array}{c}17 \text { April } \\
-15 \\
\text { Mei }\end{array}$ & Per 1 Jam \\
\hline 3 & $\begin{array}{c}\text { Pel. } \\
\text { Ciwandan - } \\
\text { Banten }\end{array}$ & $\begin{array}{c}17 \text { April } \\
-15 \\
\text { Mei }\end{array}$ & Per 1 Jam \\
\hline 4 & $\begin{array}{l}\text { Serang - } \\
\text { Banten }\end{array}$ & $\begin{array}{c}17 \text { April } \\
-15 \\
\text { Mei }\end{array}$ & Per 1 Jam \\
\hline 5 & $\begin{array}{l}\text { Sunda kelapa } \\
\text { - DKI Jakarta }\end{array}$ & $\begin{array}{c}17 \text { April } \\
-15 \\
\text { Mei }\end{array}$ & Per 1 Jam \\
\hline 6 & $\begin{array}{c}\text { Pondok } \\
\text { Dayung - } \\
\text { DKI Jakarta }\end{array}$ & $\begin{array}{c}17 \text { April } \\
-15 \\
\text { Mei }\end{array}$ & Per 1 Jam \\
\hline 7 & $\begin{array}{c}\text { Pameungpeuk } \\
\text { - Jawa Barat }\end{array}$ & $\begin{array}{c}17 \text { April } \\
-15 \\
\text { Mei }\end{array}$ & Per 1 Jam \\
\hline 8 & $\begin{array}{c}\text { Pamayang } \\
\text { Sari - Jawa } \\
\text { Barat }\end{array}$ & $\begin{array}{c}17 \text { April } \\
-15 \\
\text { Mei }\end{array}$ & Per 1 Jam \\
\hline
\end{tabular}

Perhitungan akhir yang digunakan dalam memprediksi karakteristik pasut pada masingmasing lokasi adalah dengan menghitung nilai bilangan Formzahl menggunakan nilai Amplitudo yang dihasilkan pada perhitungan pasut (Rochman, 1987). Adapun rumusnya sebagai berikut :

$$
F=\frac{\mathrm{AK}_{1}+\mathrm{AO}_{1}}{\mathrm{AM}_{2}+\mathrm{AS}_{2}}
$$

Dimana hasil dari nilai $\mathrm{F}$ akan menentukan tipe pasang surutnya, dengan klasifikasi sebagai berikut :

$0<\mathrm{F} \leq 0,25 \quad$ : Pasang surut harian ganda (semidiurnal)

$0,25<\mathrm{F} \leq 1,50 \quad$ : Pasang surut campuran condong ke harian ganda

$1,50<\mathrm{F} \leq 3,00 \quad$ : $\quad$ Pasang surut campuran condong ke harian tunggal

$\mathrm{F}>3,0 \quad$ : Pasang surut harian tunggal (diurnal)

\section{HASIL DAN PEMBAHASAN}

Hasil perhitungan admiralty menunjukan bahwa kondisi pasut dengan jarak antar stasiun kurang dari $50 \mathrm{~km}$ memiliki karakteristik yang sama. Adapun hasilnya adalah sebagai berikut:

1. Perbandingan Data Stasiun Malahayati dengan Stasiun Ulee Lhue

Nilai F pada Stasiun Malahayati adalah sebesar 0.75774 dan Stasiun Ulee Lhue adalah sebesar 0.91347. itu artinya Karakteristik pasut ada kedua lokasi adalah Pasut Harian Campuran Condong ke Harian Ganda. 
Tabel 2. Hasil Pengolahan Data Stasiun Malahayati dengan Stasiun Ulee Lhue (Kedua Stasiun Berjarak $31.66 \mathrm{~km}$ )

\begin{tabular}{|c|c|c|c|c|}
\hline \multirow{2}{*}{$\begin{array}{l}\text { Konstanta } \\
\text { Harmonik } \\
\text { Pasut }\end{array}$} & \multicolumn{2}{|c|}{ Stasiun Malahayati } & \multicolumn{2}{|c|}{ Stasiun Ulee Lhue } \\
\hline & Fase $\left({ }^{\circ}\right)$ & Amplitudo (cm) & Fase $\left({ }^{\circ}\right)$ & Amplitudo $(\mathrm{cm})$ \\
\hline S0 & - & 95.69684 & - & 58.17672 \\
\hline M2 & 74.46378 & 51.37578 & 70.53018 & 42.61808 \\
\hline $\mathrm{S} 2$ & 138.61553 & 23.51230 & 138.98114 & 19.76060 \\
\hline $\mathrm{N} 2$ & 345.74655 & 11.51498 & 350.17094 & 8.16557 \\
\hline K1 & 180.79049 & 14.70447 & 161.81088 & 13.33017 \\
\hline $\mathrm{O} 1$ & 1.80805 & 44.33925 & 1.59803 & 45.90740 \\
\hline M4 & 121.89288 & 0.74331 & 5.13840 & 0.32831 \\
\hline MS4 & 89.86229 & 1.14661 & 283.60869 & 1.02733 \\
\hline $\mathrm{K} 2$ & 138.61553 & 6.34832 & 138.98114 & 5.33536 \\
\hline $\mathrm{P} 1$ & 180.79049 & 4.85248 & 161.81088 & 4.39895 \\
\hline$F$ & \multicolumn{2}{|l|}{0.78843} & \multicolumn{2}{|l|}{0.94964} \\
\hline $\begin{array}{l}\text { Tipe } \\
\text { Pasut }\end{array}$ & \multicolumn{2}{|c|}{$\begin{array}{l}\text { Pasut Harian Campuran Condong ke Harian } \\
\text { Ganda }\end{array}$} & \multicolumn{2}{|c|}{$\begin{array}{l}\text { Pasut Harian Campuran Condong ke } \\
\text { Harian Ganda }\end{array}$} \\
\hline
\end{tabular}
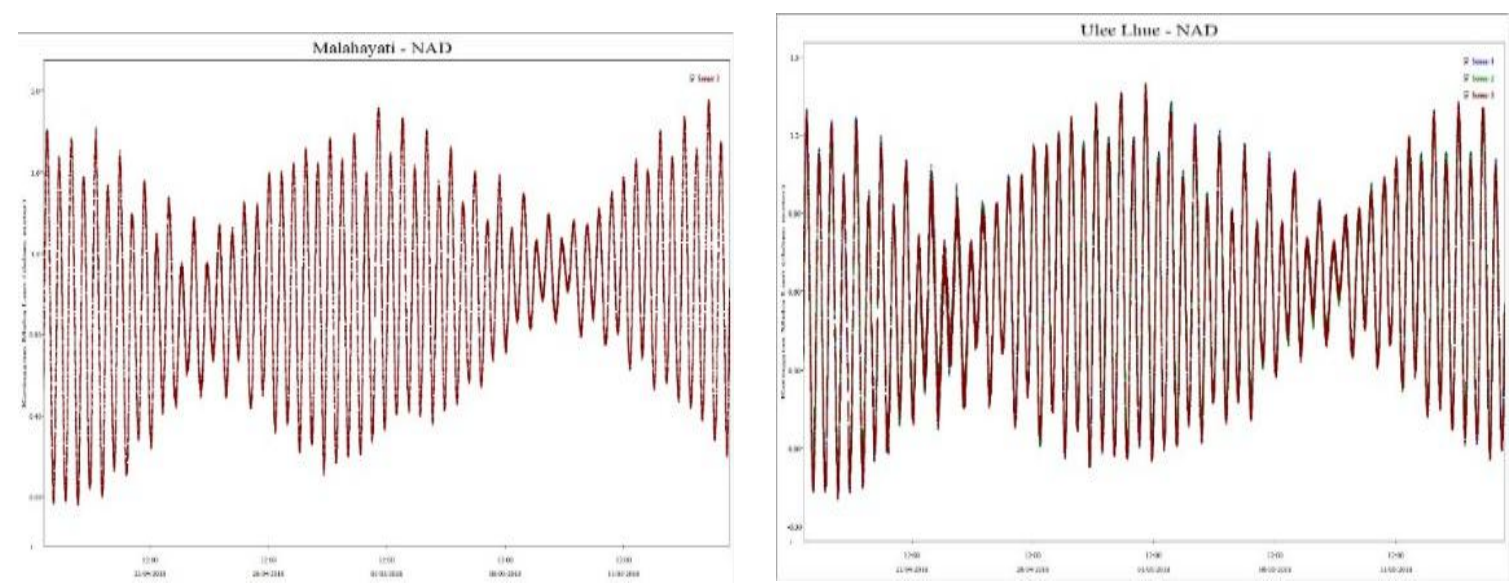

Gambar 2. Model Pasut pada Stasiun Malahayati (kiri) dan Stasiun Ulee Lhue (kanan) 
2. Perbandingan Data Stasiun Pel.Ciwandan dan Stasiun Serang

Nilai F pada Stasiun Pel.Ciwandan adalah sebesar 1.80965 dan Stasiun Serang adalah sebesar 1.36245. itu artinya Karakteristik pasut pada stasiun Pel. Ciwandan adalah Pasut Harian Campuran Condong ke Harian Tunggal dan Pasut Harian Campuran Condong ke Harian Ganda pada stasiun Serang.

Tabel 3. Hasil Pengolahan Data Stasiun Pel. Ciwandan dengan Serang (Kedua Stasiun Berjarak 26.09 km)

\begin{tabular}{|c|c|c|c|c|}
\hline \multirow{2}{*}{$\begin{array}{l}\text { Konstanta } \\
\text { Harmonik } \\
\text { Pasut }\end{array}$} & \multicolumn{2}{|c|}{ Stasiun Pel. Ciwandan } & \multicolumn{2}{|c|}{ Stasiun Serang } \\
\hline & Fase $\left(^{\circ}\right)$ & Amplitudo (cm) & Fase $\left(^{\circ}\right)$ & Amplitudo (cm) \\
\hline S0 & - & 129.51006 & - & 64.81466 \\
\hline M2 & 332.43087 & 22.05532 & 334.08667 & 30.56938 \\
\hline $\mathrm{S} 2$ & 13.14745 & 11.80403 & 18.26690 & 13.90792 \\
\hline $\mathrm{N} 2$ & 246.11805 & 3.62590 & 257.18748 & 5.59078 \\
\hline K1 & 61.87013 & 17.94525 & 214.22242 & 16.15341 \\
\hline $\mathrm{O} 1$ & 9.44224 & 46.09761 & 5.04652 & 46.91195 \\
\hline M4 & 225.45160 & 0.76191 & 5.91091 & 0.48714 \\
\hline MS4 & 83.36600 & 1.07122 & 295.67597 & 1.39574 \\
\hline $\mathrm{K} 2$ & 13.14745 & 3.18709 & 18.26690 & 3.75514 \\
\hline $\mathrm{P} 1$ & 61.87013 & 5.92193 & 214.22242 & 5.33063 \\
\hline$F$ & \multicolumn{2}{|l|}{1.89144} & \multicolumn{2}{|l|}{1.41792} \\
\hline Tipe Pasut & \multicolumn{2}{|c|}{$\begin{array}{l}\text { Pasut Harian Campuran Condong ke Harian } \\
\text { Tunggal }\end{array}$} & \multicolumn{2}{|c|}{$\begin{array}{l}\text { Pasut Harian Campuran Condong ke } \\
\text { Harian Ganda }\end{array}$} \\
\hline
\end{tabular}

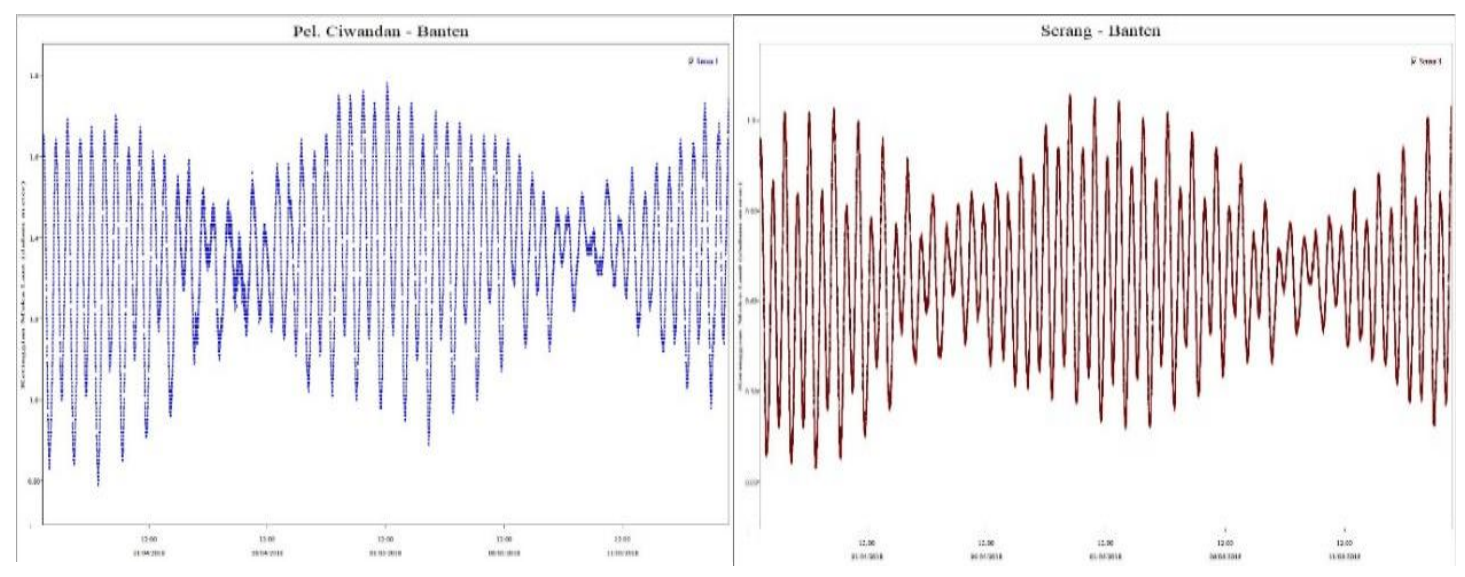


Gambar 3. Model Pasut pada Stasiun Pel. Ciwandan (kiri) dan Stasiun Serang (kanan)

3. Perbandingan Data Stasiun Sunda Kelapa dengan Stasiun Pondok Dayung

Nilai F pada Stasiun Sunda Kelapa adalah sebesar 8.85750 dan Stasiun Pondok Dayung adalah sebesar 6.70224. itu artinya Karakteristik pasut ada kedua lokasi adalah Pasut Harian Tunggal.

Tabel 4. Hasil Pengolahan Data Stasiun Sunda Kelapa dengan Pondok Dayung (Kedua Stasiun Berjarak $13.05 \mathrm{~km}$ )

\begin{tabular}{|c|c|c|c|c|}
\hline \multirow{2}{*}{$\begin{array}{l}\text { Konstanta } \\
\text { Harmonik Pasut }\end{array}$} & \multicolumn{2}{|c|}{ Stasiun Sunda Kelapa } & \multicolumn{2}{|c|}{ Stasiun Pondok Dayung } \\
\hline & Fase $\left({ }^{\circ}\right)$ & Amplitudo (cm) & Fase $\left({ }^{\circ}\right)$ & Amplitudo (cm) \\
\hline S0 & - & 897.02730 & - & 134.29023 \\
\hline M2 & 193.41404 & 6.50578 & 30.26860 & 5.78173 \\
\hline $\mathrm{S} 2$ & 11.82509 & 4.56410 & 17.85389 & 5.07584 \\
\hline $\mathrm{N} 2$ & 143.50254 & 3.37228 & 134.24945 & 2.56873 \\
\hline $\mathrm{K} 1$ & 65.03694 & 71.03296 & 108.44346 & 30.69920 \\
\hline $\mathrm{O} 1$ & 35.87981 & 33.95378 & 22.03583 & 46.57824 \\
\hline M4 & 74.95696 & 0.16904 & 50.57595 & 0.32708 \\
\hline MS4 & 28.49069 & 0.75704 & 44.26031 & 0.92813 \\
\hline $\mathrm{K} 2$ & 11.82509 & 1.23231 & 17.85389 & 1.37048 \\
\hline $\mathrm{P} 1$ & 65.03694 & 23.44088 & 108.44346 & 10.13074 \\
\hline$F$ & 9.48400 & & 7.11738 & \\
\hline Tipe Pasut & Pasut Harian Tunggal & & Pasut Harian Tunggal & \\
\hline
\end{tabular}
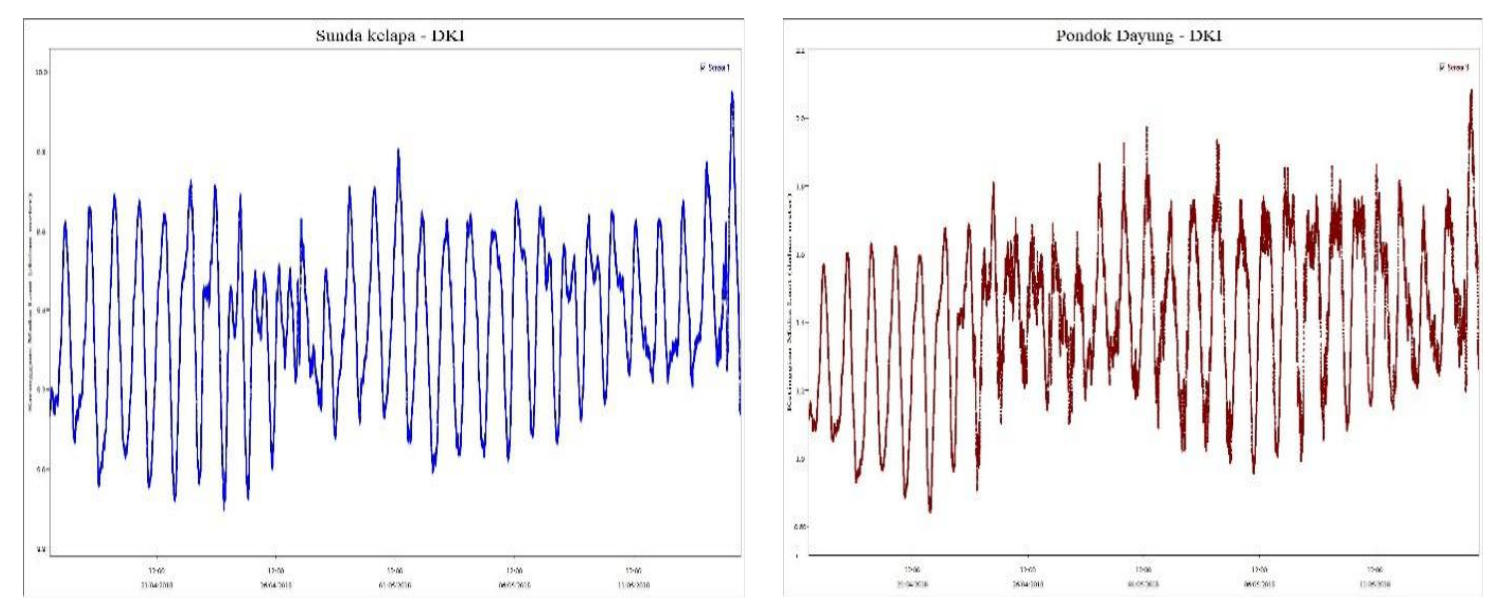

Gambar 4. Model Pasut pada Stasiun Sunda Kelapa (kiri) dan Stasiun Pondok Dayung (kanan) 
4. Perbandingan Data Stasiun Pamengpeuk dengan Stasiun Pamayangsari

Nilai F pada Stasiun Pamengpeuk adalah sebesar 1.50563 dan Stasiun Pamayangsari adalah sebesar 1.02946. itu artinya Karakteristik pasut pada Stasiun Pamengpeuk adalah Pasang Surut Harian Campuran Condong ke Harian Tunggal dan Pasang Surut Harian Campuran Condong ke Harian Ganda pada stasiun Pamayangsari.

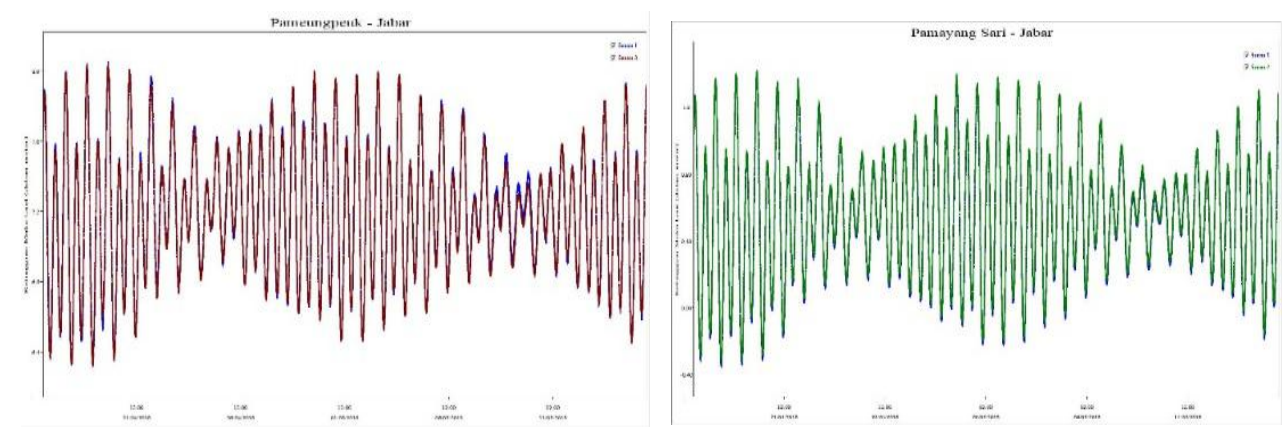

Gambar 5. Model Pasut pada Stasiun Pamengpeuk (kiri) dan Stasiun Pemayang Sari (kanan)

Tabel 5. Hasil Pengolahan Data Stasiun Pameungpeuk dengan Pamayangsari (Kedua Stasiun Berjarak $49.64 \mathrm{~km}$ )

\begin{tabular}{lrrrr}
\hline $\begin{array}{l}\text { Konstanta } \\
\text { Harmonik } \\
\text { Pasut }\end{array}$ & \multicolumn{2}{c}{ Stasiun Pameungpeuk } & \multicolumn{2}{c}{ Stasiun Pamayangsari } \\
\hline & \multicolumn{1}{c}{ Fase $\left(^{\circ}\right)$} & Amplitudo $(\mathrm{cm})$ & \multicolumn{1}{c}{ Fase $\left(^{\circ}\right)$} & Amplitudo $(\mathrm{cm})$ \\
\hline S0 & 690.23851 & - & 52.13937 \\
M2 & 319.43616 & 43.00508 & 315.70489 & 44.49334 \\
S2 & 2.52606 & 19.41037 & 356.95204 & 20.79562 \\
N2 & 245.57955 & 8.46308 & 249.69853 & 8.28398 \\
K1 & 215.47736 & 68.33926 & 193.07909 & 23.15421 \\
O1 & 1.97607 & 31.42506 & 358.19247 & 47.06994 \\
M4 & 334.58721 & 0.37297 & 7.15398 & 0.41618 \\
MS4 & 96.74135 & 0.93847 & 286.05052 & 1.31341
\end{tabular}




\section{KESIMPULAN}

Pada stasiun Malahayati dan Ulee Lhue memiliki tipe pasut yang sama, yaitu Pasut Harian Campuran Condong ke Harian Ganda. Stasiun Sunda Kelapa dan Pondok Dayung juga memiliki tipe pasut yang sama yaitu Pasut Harian Tunggal. Baik Malahayati dan Ulee Lhue maupun Sunda Kelapa dengan Pondok Dayung penempatan stasiun berada pada lokasi yang kondisi perairannya sama.

Sedangkan Stasiun Pel. Ciwandan dengan Serang memiliki tipe pasut Campuran namun condong ke tipe pasut yang berbeda. Pel. Ciwandan lebih Condong ke Harian Tunggal sedangkan stasiun Serang lebih condong ke Harian Ganda. Hal ini juga sama dengan yang terjadi pada stasiun Pameungpeuk dengan Pamayangsari. Perbedaan ini dikarenakan penempatan lokasi stasiun pada tipe perairan yang berbeda. Perbedaan ini bisa saja dipengaruhi oleh penempatan stasiun pasut yang kondisi morfologi pantainya berbeda. Selain itu kemungkinan lain bisa disebabkan oleh penjalran pasang surut pada kondisi batimetri yang kompleks seperti terdapatnya selat, palung dan laut yang dangkal dan laut dalam. Keadaan perairan tersebut membentuk pola pasang surut yang beragam (Ongkosongo, 1989). 


\section{UCAPAN TERIMA KASIH}

Ditujukan kepada pihak-pihak yang membantu penulis kepada Panitia SENBA BMKG 2019 yang telah memberikan kesempatan kepada penulis sehingga tulisan ini dapat dipublikasikan, terimakasih juga kepada Badan Informasi Geospasial yang telah menyediakan data-data penelitian.

\section{DAFTAR PUSTAKA}

Ahmad, R., Hendry, A., Fauzi, M., 2017. Pengaruh Simulasi Awal Data Pengamatan Terhadap Efektivitas Prediksi Pasang Surut Metode Admiralty (Studi Kasus Pelabuhan Dumai). Jom FTEKNIK Volume 4 No.2. Universitas Riau

Ali, M., Mihardja D.K., dan Hadi, S., 1994. Pasang Surut Laut. Institut Teknologi Bandung. Bandung.

SNI 7924:2013, Instalasi Stasiun Pasang Surut, Badan Standardisasi Nasional, Jakarta

http://www.inasealevelmonitoring.big.go.id/ipasoet/, lokasi stasiun pasut Badan Informasi Geospasial, diakses pada 10 Maret 2019

Pariwono, J.I., 1989. Gaya Penggerak Pasang Surut. Dalam Pasang Surut. Penyunting Ongkosongo dan Suyarso. Puslitbang Oseanologi LIPI. Jakarta.

Ongkosongo dan Suyarso, 1989. Pasang Surut. Jakarta: Pusat Penelitian dan Pengembagan Oseanologi LIPI.

Rochman, D., 1987. Cara Perhitungan Pasut Laut Dengan Metode Admiralty. Dinas Pemetaan Topografi, Badan Koordinasi Survey dan Pemetaan Nasional (Bakosurtanal). Cibinong, Bogor.
Fitriana, Dina., Setyawan, Irfan M., 2018. Akuisisi Data Stasiun Pasang Surut untuk Datum Pasang Surut 2036. Conference of Geospatial Information Science and Engineering-CGISE. Yogyakarta.

Hidayat, S. (2010). Analasis Harmonik Pasang Surut dengan Metode Admiralty (Studi Kasus Pelabuhan Beras, Bontang, Kalimantan Timur. Bogor: Institut Pertanian Bogor.

Supriyono dkk., 2015. Analisa dan Perhitungan Prediksi Pasang Surut Menggunakan Metode Admiralty dan Metode Lest Square (Studi Kasus Perairan Tarakan dan Balikpapan). Jurnal Chart Datum Vol.1. Sekolah Tinggi Angkatan Laut. Jakarta.

Triatmodjo, B. (1999). Teknik Pantai.Yogyakarta: Beta Offset. 